\title{
Temperature corrected ready-reckoner chart for determination of dry rubber content in Hevea latex using the Metrolac
}

\author{
K V V S Kudaligama*, G V L Nilmini*, V H L Rodrigo* and \\ R P S Randunu*
}

*Rubber Research Institute, Dartonfield, Agalawatta

Received: 05 April 2014

\begin{abstract}
Rubber latex is collected by periodic excision of a thin shaving of the bark of Hevea tree. In addition to the volume, its value is determined by the dry rubber content (DRC) of latex. Dry rubber content of latex varies usually in the range of 20-45\% and depends on several factors such as clone, season, climate and weather condition, stimulation program, tapping system, soil condition etc. Hydrometry (using the Metrolac) is the most widely used method in the determination of DRC in the Sri Lankan rubber industry. Metrolac measurements are highly vulnerable to temperature of the latex/water mixture. Existing ready-reckoner for Metrolac readings is valid only at $29^{\circ} \mathrm{C}$, hence the present study was aimed at developing a Metrolac ready-reckoner chart corrected for temperature variation in latex. Under natural and adjusted conditions, the new ready-reckoner chart showed an accuracy level of $84 \%$ on average in the estimation of dry rubber content whilst the average accuracy by the existing chart was below 50\%. The Metrolac estimated DRC differed in the range of $-12.69 \%$ to $9.25 \%$ from the actual under existing ready reckoner whilst that was limited to $-7.56 \%$ to $5.31 \%$ with the use of new ready-reckoner chart.
\end{abstract}

Key words: dry rubber content, DRC, Hevea, hydrometer, ready-reckoner, rubber latex, tapping metrolac, temperature

\section{Introduction}

Rubber is one of the major agricultural crops in Sri Lanka. Even though there are several accurate methods for determination of dry rubber content (DRC) in rubber latex, Metrolac is widely used in Sri Lanka due to the convenience in field use. Standard laboratory method which is more accurate in DRC determination (Anon, 1984) needs costly equipments such as analytical balances and also takes considerable time duration. The first ready-reckoner chart for Metrolac/ 
latexometer was introduced in early 1900s (Campbell, 1916) and later on with several amendments, the existing ready-reckoner chart has been developed. In order to avoid the temperature variations, values given in existing ready reckoner were standardised at $29^{\circ} \mathrm{C}$. However in field conditions, temperature of the latex water mixture prepared for determination of Metrolac reading varies in a wide range. Specially in non traditional rubber growing areas (i.e. Nuwaraeliya and Badulla Districts in up country region and Moneragala and Ampara Districts in low country Intermediate zone), temperature variations from $17{ }^{\circ} \mathrm{C}$ to $32{ }^{\circ} \mathrm{C}$ in the latex water mixture is evident. Even in traditional rubber growing areas such temperature variations may occur under extreme weather conditions. Metrolac is a hydrometer working on up-thrust principle in liquid. Rubber is less dense than water; hence in order to measure the DRC, it's scale has been prepared opposite to general hydrometer. Metrolac reading appreciates with temperature increase and vice versa. Rubber harvesters are provided with an incentive payment and it is based on amount of dry rubber harvested. As the determination of DRC is made with Metrolac, some harvesters try to manipulate its reading by adding hot water to latex or keeping the latex under sunlight. This will give an inflated DRC value. Also, latex collectors for large factories collect latex during day time and unload in late nights. Under the low temperatures prevailing at nights, collectors get lower values of DRC for their latex. This tends to over/under estimate the rubber content causing undue financial losses/gains. Therefore, this study attempted to develop a temperature corrected readyreckoner chart for determination of dry rubber content in rubber latex using the Metrolac.

\section{Methodology \\ Development of the temperature corrected ready-reckoner chart}

About 400 fresh latex samples were collected and one fold of latex from each sample was mixed with two folds of clean water as per the requirements for Metrolac latex weighing (Sarath Kumara, 2003). Temperature of these latex water mixtures was adjusted using an ice bath or a hot water bath and Metrolac reading was taken at each degree from $15^{\circ} \mathrm{C}$ to $35^{\circ} \mathrm{C}$. To determine the Metrolac reading, the above mentioned latex water samples were poured separately into a cylinder until it overflows. After removing froth Metrolac is immersed into the latex water mixture slowly. Once settled, the reading on the stem of Metrolac at the meniscus was taken. Using a readyreckoner Metrolac chart, the DRC of latex (MDRC) was estimated.

Since existing Metrolac ready-reckoner chart had been standardised at $29^{\circ} \mathrm{C}$, corresponding dry rubber content given in the Metrolac ready-reckoner chart (at $29^{\circ} \mathrm{C}$ ) was taken as the base value for building up the temperature corrected 
ready-reckoner Metrolac chart. Linear relationship of MDRC estimated at $29^{\circ} \mathrm{C}$ of latex samples were regressed with MDRC estimated at each degree of temperature and equations were built up for the linear relationships between MDRC at $29^{\circ} \mathrm{C}$ and different temperatures. Using these equations the MDRC at each temperature for different Metrolac readings was estimated and developed the ready-reckoner chart for estimation of dry rubber content with temperature correction.

\section{Validation of new ready-reckoner}

About 400 fresh latex samples were collected from Dartonfield estate in Kalutara District, Sanquhar estate in Nuwaraeliya District and Keppetigala estate in Kurunegala district. As per the requirements for Metrolac reading one fold of latex sample was mixed with two folds of clean water for DRC estimation with Metrolac. Temperature of the mixture of latex/water was measured at the point of taking the Metrolac reading.

In addition, Metrolac reading of about 140 latex samples was measured by adjusting the temperature of latex water/mixture with the use of hot or cold water for latex dilution. Actual dry rubber content of each sample was determined by the standard laboratory method (Anon, 1984).

\section{Results and Disscussion}

Metrolac is also a kind of hydrometer. Therefore, temperature of the latex water mixture used for assessing the
DRC is critical as it affects the density and hence the upward thrust. The Metrolac is calibrated at $29^{\circ} \mathrm{C}$, so that any variation of the temperature of latex/water weighing mixture will give an erroneous reading. In the temperatures below $29^{\circ} \mathrm{C}$ the thermal contraction of weighing mixture increases the density and Metrolac moves upward underestimating the dry rubber content of latex. Similarly thermal expansion of latex mixture above $29^{\circ} \mathrm{C}$ over estimates the dry rubber content of latex. Therefore, accuracy of the Metrolac reading is highly dependent on the temperature of the mixture of latex/water. Dry rubber content estimated with the Metrolac readings taken at each temperature were regressed with the dry rubber content estimated at $29^{\circ} \mathrm{C}$ and equations were developed to quantify the difference in Metrolac dry rubber content (MDRC) observed due to the difference in temperature of weighing mixture. Using the equations developed appropriate Metrolac readings at each temperature was estimated and the new readyreckoner chart was developed against the temperature of weighing mixture (Table 1).

To investigate the performance of the new chart for the estimation of dry rubber content, two series of sample sets were analysed, i.e. to investigate the feasibility of estimating the DRC of latex with Metrolac under natural environment and adjusted conditions. 
Table 1. Temperature corrected ready-reckoner chart for the estimation of dry rubber content of latex with Metrolac

TEMPERATURE* $\left({ }^{\circ} \mathrm{C}\right)$

\begin{tabular}{|c|c|c|c|c|c|c|c|c|c|c|c|c|c|c|c|c|c|c|c|c|c|c|}
\hline & 15 & 16 & 17 & 18 & 19 & 20 & 21 & 22 & 23 & 24 & 25 & 26 & 27 & 28 & 29 & 30 & 31 & 32 & 33 & 34 & 35 & \\
\hline 50 & 0.34 & 0.33 & 0.32 & 0.31 & 0.30 & 0.29 & 0.28 & 0.27 & 0.26 & 0.25 & 0.24 & 0.23 & 0.22 & 0.21 & 0.20 & 0.19 & 0.18 & 0.17 & 0.17 & 0.16 & 0.15 & 50 \\
\hline 60 & 0.36 & 0.35 & 0.34 & 0.33 & 0.32 & 0.31 & 0.30 & 0.29 & 0.28 & 0.27 & 0.26 & 0.25 & 0.24 & 0.23 & 0.22 & 0.21 & 0.20 & 0.19 & 0.19 & 0.18 & 0.17 & 60 \\
\hline 70 & 0.38 & 0.37 & 0.36 & 0.35 & 0.34 & 0.33 & 0.32 & 0.31 & 0.30 & 0.29 & 0.28 & 0.27 & 0.26 & 0.25 & 0.24 & 0.23 & 0.22 & 0.21 & 0.21 & 0.20 & 0.19 & 70 \\
\hline 80 & 0.40 & 0.39 & 0.38 & 0.37 & 0.36 & 0.35 & 0.34 & 0.33 & 0.32 & 0.31 & 0.30 & 0.29 & 0.28 & 0.27 & 0.26 & 0.25 & 0.24 & 0.23 & 0.23 & 0.22 & 0.21 & 80 \\
\hline 90 & 0.42 & 0.41 & 0.40 & 0.39 & 0.38 & 0.37 & 0.36 & 0.35 & 0.34 & 0.33 & 0.32 & 0.31 & 0.30 & 0.29 & 0.28 & 0.27 & 0.26 & 0.25 & 0.24 & 0.24 & 0.23 & 90 \\
\hline 100 & 0.44 & 0.43 & 0.42 & 0.41 & 0.40 & 0.39 & 0.38 & 0.37 & 0.36 & 0.35 & 0.34 & 0.33 & 0.32 & 0.31 & 0.30 & 0.29 & 0.28 & 0.27 & 0.26 & 0.25 & 0.24 & 100 \\
\hline 110 & 0.46 & 0.45 & 0.44 & 0.43 & 0.42 & 0.41 & 0.40 & 0.39 & 0.38 & 0.37 & 0.36 & 0.35 & 0.34 & 0.33 & 0.32 & 0.31 & 0.30 & 0.29 & 0.28 & 0.27 & 0.26 & 110 \\
\hline 120 & 0.48 & 0.47 & 0.46 & 0.45 & 0.44 & 0.43 & 0.42 & 0.41 & 0.40 & 0.39 & 0.38 & 0.37 & 0.36 & 0.35 & 0.34 & 0.33 & 0.32 & 0.31 & 0.30 & 0.29 & 0.28 & 120 \\
\hline 130 & 0.50 & 0.49 & 0.48 & 0.47 & 0.46 & 0.45 & 0.44 & 0.43 & 0.42 & 0.41 & 0.40 & 0.39 & 0.38 & 0.37 & 0.36 & 0.35 & 0.34 & 0.33 & 0.32 & 0.31 & 0.30 & 130 \\
\hline 140 & 0.52 & 0.51 & 0.50 & 0.49 & 0.48 & 0.47 & 0.46 & 0.45 & 0.44 & 0.43 & 0.42 & 0.41 & 0.40 & 0.39 & 0.38 & 0.37 & 0.36 & 0.35 & 0.34 & 0.33 & 0.32 & 140 \\
\hline 150 & 0.54 & 0.53 & 0.52 & 0.51 & 0.50 & 0.49 & 0.48 & 0.47 & 0.46 & 0.45 & 0.44 & 0.43 & 0.42 & 0.41 & 0.40 & 0.39 & 0.38 & 0.37 & 0.36 & 0.35 & 0.34 & 150 \\
\hline
\end{tabular}

(Dilution: 1 part of latex to 2 parts of water

*Temperature of 1:2 diluted latex water mixture at the time of Metrolac reading) 
Under natural and adjusted conditions the new ready-reckoner chart showed an accuracy level of $84 \%$ on average $\left(R^{2}=\right.$ $0.84)$ in the estimation of dry rubber content whilst the average accuracy by the existing chart was below $50 \%\left(R^{2}=\right.$
0.49) (Fig. 1). Particularly at high level of actual DRC i.e. what determined in the laboratory (LDRC) the estimated DRC by Metrolac (MDRC) tended to be low with both ready-reckoner charts.

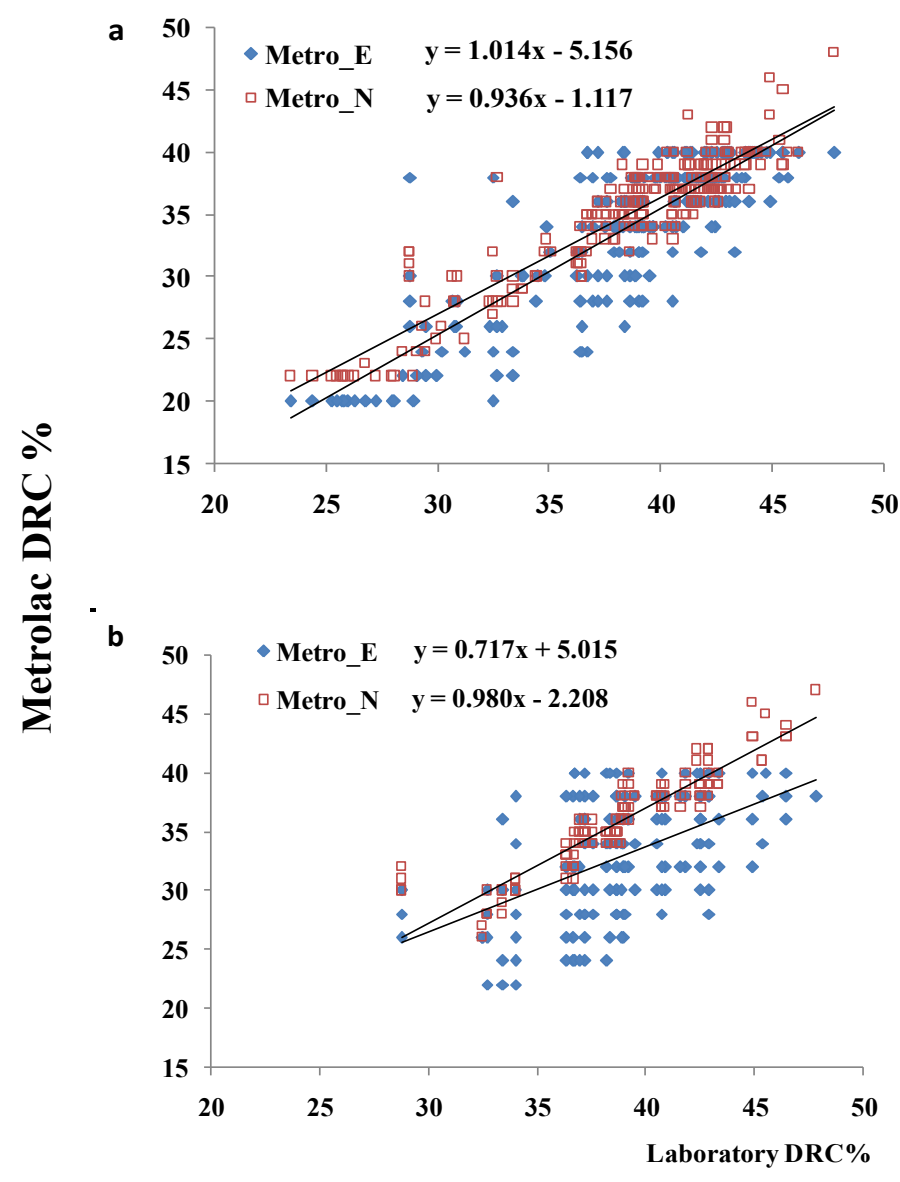

Fig. 1. Relationship of dry rubber content \% estimated with Metrolac using existing (Metro_E) and new (Metro_N) ready-reckoner charts with percentage dry rubber content assessed in the laboratory under a) natural conditions and b) artificially simulated temperatures 
No special pattern was found in the observed difference of the estimated MDRC from LDRC in the samples tested under both natural and artificially simulated temperatures. Under natural conditions, observed difference in MDRC from LDRC was between $12.69 \%$ to $9.25 \%$ when using the existing ready-reckoner whilst difference of the estimated values with the new chart was between $-7.56 \%$ to $5.31 \%$ (Fig. 2). In the latex samples in which the different temperatures were artificially simulated the observed difference in MDRC from LDRC was between $-14.89 \%$ to $4.00 \%$ with the existing ready-reckoner and this difference was limited to $-6.48 \%$ to $3.25 \%$ with the use of new readyreckoner chart (Fig. 2).

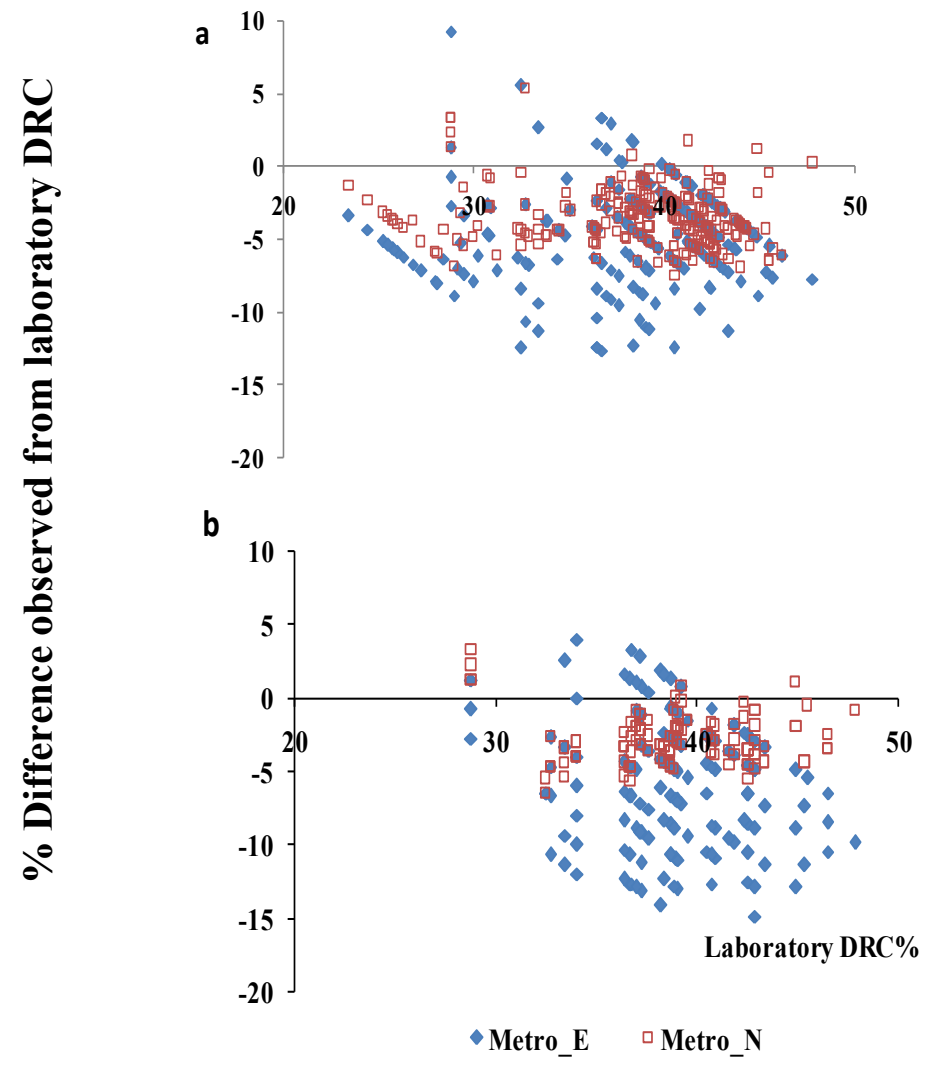

Fig. 2. Difference observed in the dry rubber content \% estimated with Metrolac with the use of existing (Metro_E) and new (Metro_N) ready-reckoner charts and the percentage dry rubber content assessed in the laboratory under a) natural conditions and b) artificially simulated temperatures 
At lower temperatures $\left(<29^{\circ} \mathrm{C}\right)$, DRC determined with the existing chart is underestimated and difference observed between MDRC and LDRC was greater. As expected, this variation becomes narrower at around $29^{\circ} \mathrm{C}$ and then leads to over estimation $\left(>29^{\circ} \mathrm{C}\right)$. Deviation of temperature by $1{ }^{\circ} \mathrm{C}$ in latex mixture used for weighing has resulted in $0.91 \%$ variation in DRC estimated with the existing ready-reckoner chart (Fig. 3). Because of temperature correction, no such variation was observed with new ready-reckoner chart.

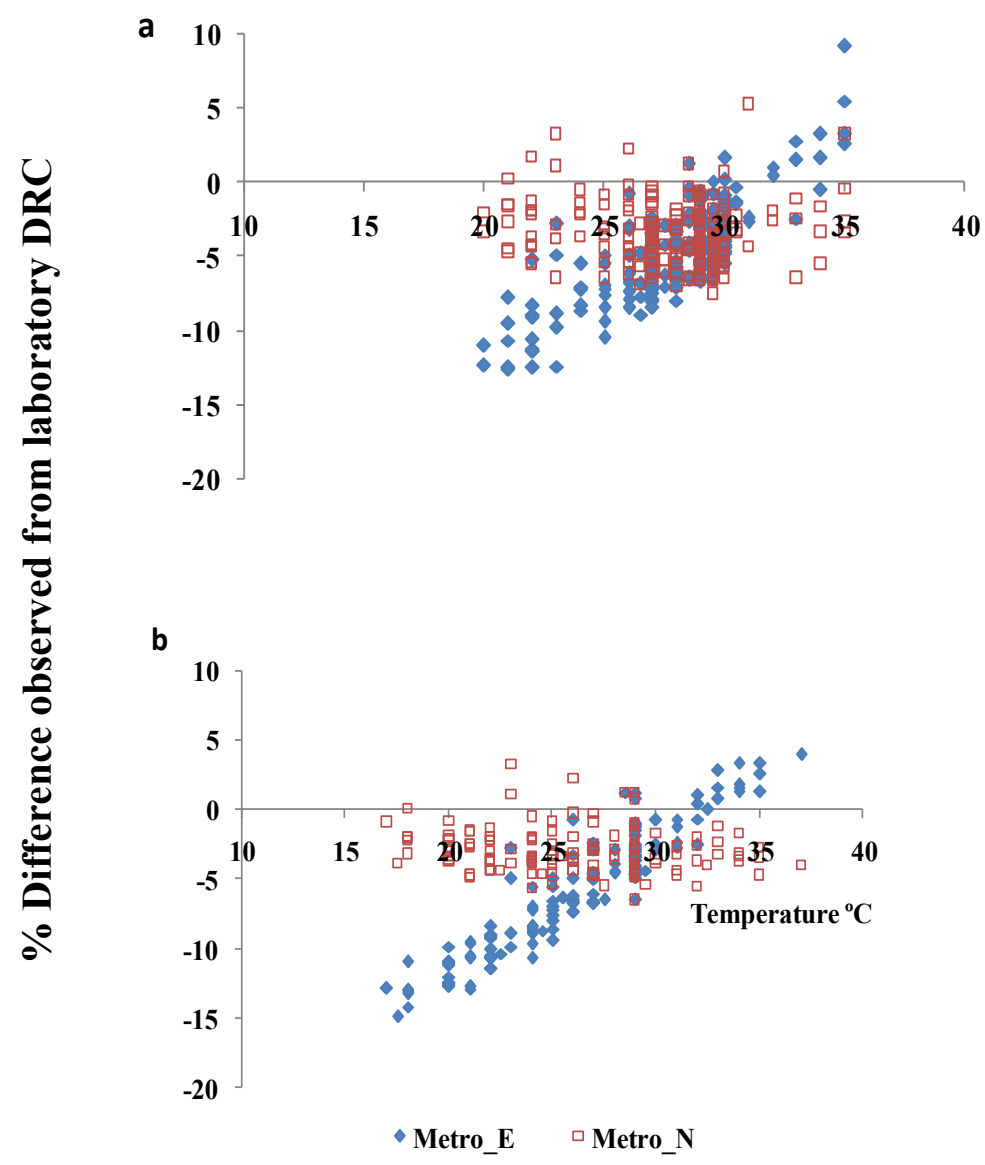

Fig. 3. Difference observed in the dry rubber content $\%$ estimated with Metrolac with the use of existing (Metro_E) and new (Metro_N) ready-reckoner charts and the temperature of weighing mixture under a) natural conditions and b) artificially simulated temperatures 
The effect of tree age, regional climate and seasonal changes in tree physiology on the accuracy of Metrolac reading is found to be not significant (Sarath Kumara and Prasad, 2006). Addition of adulterants such as plant sap, soapy water has a possibility of making the latex more viscous and affects the free movement of the Metrolac giving false reading. No effect on the estimation of DRC with Metrolac has been recorded with the use of preservatives, if applied within the recommended levels (Sarath Kumara and Prasad, 2006). Addition of water having the same temperature can cause errors in the estimation of DRC in latex with Metrolac as variation of density of latex against dilution with water has no any linear relationship (Sarath Kumara and Prasad, 2006). Apart from the effect of the factors discussed above, procedural errors such as improper straining, dilution and mixing of latex and incorrect judging of reading at meniscus also give erratic values in DRC estimation and those could not be rectified even by the new temperature corrected ready-reckoner chart.

\section{References}

Anon (1984). Determination of dry rubber content of latex ISO 126:1995(E), ISO Standards Hand Book 22, Volume 1 \& 2. International Standard Organization.

Campbell, W B (1916). Tables of ready reckoner for use with the metrolac or any type of latexometer, Kelly and Walsh, Singapore, 1-8.

Sarath Kumara, P H and Prasad, A K D W (2006). Is metrolac weighing an accurate method for DRC estimation. Bulletin of the Rubber Research Institute of Sri Lanka 47, 51-58.

Sarath Kumara, P H (2003). Latex collection. In: Handbook of Rubber Vol.2: Processing Technology pp.1-14. (Eds. L.M.K. Tillekeratne et al.), Rubber Research Institute of Sri Lanka, Agalawatta, Sri Lanka.

Address for correspondence: $\mathrm{Dr}$ (Mrs) K V V S Kudaligama, Senior Research Officer, Biochemistry \& Physiology Dept., Rubber Research Institute of Sri Lanka, Dartonfield, Agalawatta, Sri Lanka.

e-mail: vskudaligama@yahoo.com 